\title{
Spectrophotometric assessment of the effects of $10 \%$ carbamide peroxide on enamel translucency
}

\section{Glauco Fioranelli Vieira(a) \\ Yuri Arakaki ${ }^{(b)}$ \\ Taciana Marco Ferraz Caneppele(c)}

(a) Associate Professor; (b)Master's Student in Restorative Dentistry - Department of Restorative Dentistry, School of Dentistry, University of São Paulo (USP), São Paulo, SP, Brazil.

(c) Specialist in Restorative Dentistry, São Paulo Dental Association (APCD), São Paulo, SP, Brazil.

\begin{abstract}
Tooth shade results from the interaction between enamel color, enamel translucency and dentine color. A change in any of these parameters will change a tooth's color. The objective of this study was to evaluate the changes occurring in enamel translucency during a tooth whitening process. Fourteen human tooth enamel fragments, with a mean thickness of $0.96 \mathrm{~mm}( \pm 0.3 \mathrm{~mm})$, were subjected to a bleaching agent (10\% carbamide peroxide) 8 hours per day for 28 days. The enamel fragment translucency was measured by a computer controlled spectrophotometer before and after the bleaching agent applications in accordance with ANSI Z80.3-1986 - American National Standard for Ophthalmics - nonprescription sunglasses and fashion eyewear-requirements. The measurements were statistically compared by the Mann-Whitney nonparametric test. A decrease was observed in the translucency of all specimens and, consequently, there was a decrease in transmittance values for all samples. It was observed that the bleaching procedure significantly changes the enamel translucency, making it more opaque.
\end{abstract}

Descriptors: Tooth bleaching; Dental enamel; Spectrophotometry

\section{Corresponding author:}

Taciana Marco Ferraz Caneppele

R. das Arraias, $80-26$

São José dos Campos - São Paulo - Brazil CEP: 12246-330

E-mail: tacileo@uol.com.br 


\section{Introduction}

Nowadays, white, well positioned and outlined teeth not only portray a pattern of beauty, but also indicate health and oral hygiene. ${ }^{1}$

Any tooth discoloration may compromise the beauty of a smile, as the tooth color is an important factor in an attractive smile. Tooth color changes can occur on the enamel surface (extrinsic stain) or inside the tooth structure (intrinsic stain). The former often results from the precipitation of diet pigments on the bacterial plaque or enamel surface. ${ }^{2}$ It is important to mention that some structural features and some superficial characteristics of the enamel may contribute to pigment precipitation, such as roughness, porosity, and depression. ${ }^{3}$ On the other hand, intrinsic stains may result from several pre-eruptive or post-eruptive factors. In vital teeth, color changes could be natural, physiological or the result of excessive ingestion of some substances (e.g., tetracycline or fluoride). Moreover, in vital teeth, intrinsic discoloration can result from systemic diseases or traumas, which lead to an internal hemorrhage and consequently to change of the tooth color. ${ }^{1}$

In Dentistry several techniques have been indicated to rebuild a smile that has been jeopardized by a change in tooth color. However, tooth whitening has been considered an effective and conservative treatment for achieving harmony between esthetic requirements and tooth color. ${ }^{4,5} \mathrm{~A}$ large number of methods have been developed for this purpose. Different percentages of hydrogen peroxide and carbamide peroxide can be used. In vital teeth, however, carbamide peroxide has been suggested to be the safer alternative. ${ }^{6}$

Enamel color and translucency as well as dentine color determine the color of teeth. Enamel translucency affects the perception of the color, therefore the enamel acts as a light filter for dentine, which works in 2 ways, that is, when light falls on the enamel, it is transmitted to the dentine, which in turn reflects it, so that it returns to the enamel again, and is passed into the environment in the direction of the observer.

The purpose of this in vitro research was to assess the effects of a $10 \%$ carbamide peroxide agent on enamel translucency.

\section{Materials and Methods}

This study was carried out at the Restorative Dentistry Laboratory, School of Dentistry, University of São Paulo, after approval by the Ethics Committee (process 69/05).

Fourteen human tooth enamel fragments from the buccal face of fourteen human molar teeth, which were extracted for several reasons, were evaluated. The dentine was abraded with a low speed hand piece and carbide bur under cooling. The samples $-8.0 \mathrm{~mm}$ long, $4 \mathrm{~mm}$ wide and $0.96 \mathrm{~mm}$ thick $( \pm 0,3 \mathrm{~mm})$ - were made to enable them to be adapted to the spectrometer window (Cintra $10 \mathrm{UV}$ - Visible Spectrometer).

The specimens were kept moistened in distilled water at all times. The whitening agent Sorriso (Colgate-Palmolive, Brazil), 10\% carbamide peroxide, was used in accordance with the manufacturer's instructions. Each enamel fragment was positioned so that the external surface, which corresponded to the buccal face, was in contact with the gel. To ensure that the samples were kept moist, wet cotton was placed in contact with the internal surface.

Each of the 14 fragments was conditioned with the gel during 8 hours per day and the translucency of the specimens was evaluated before and after the whitening process. After this period, the samples were washed and kept moistened as described previously. The procedure was repeated during 4 weeks.

In order to measure fragment translucency, each sample was positioned in the spectrometer viewer, so that any fissure between the fragment edge and the spectrometer viewer would be noticed. It is important to mention that during the measurements the samples were kept moist and were placed against a black background.

The ANSI Z80.3-1986, American National Standard for Ophthalmics - nonprescription sunglasses and fashion eyewear - requirements was used in the research. The transmittance values were obtained between 380 and 780 nanometers.

The data were analyzed by a non-parametric test, comparing the situations (normal and bleached). The Mann-Whitney test was performed at a 5\% level of significance $(\mathrm{p} \leq 0.05)$. 


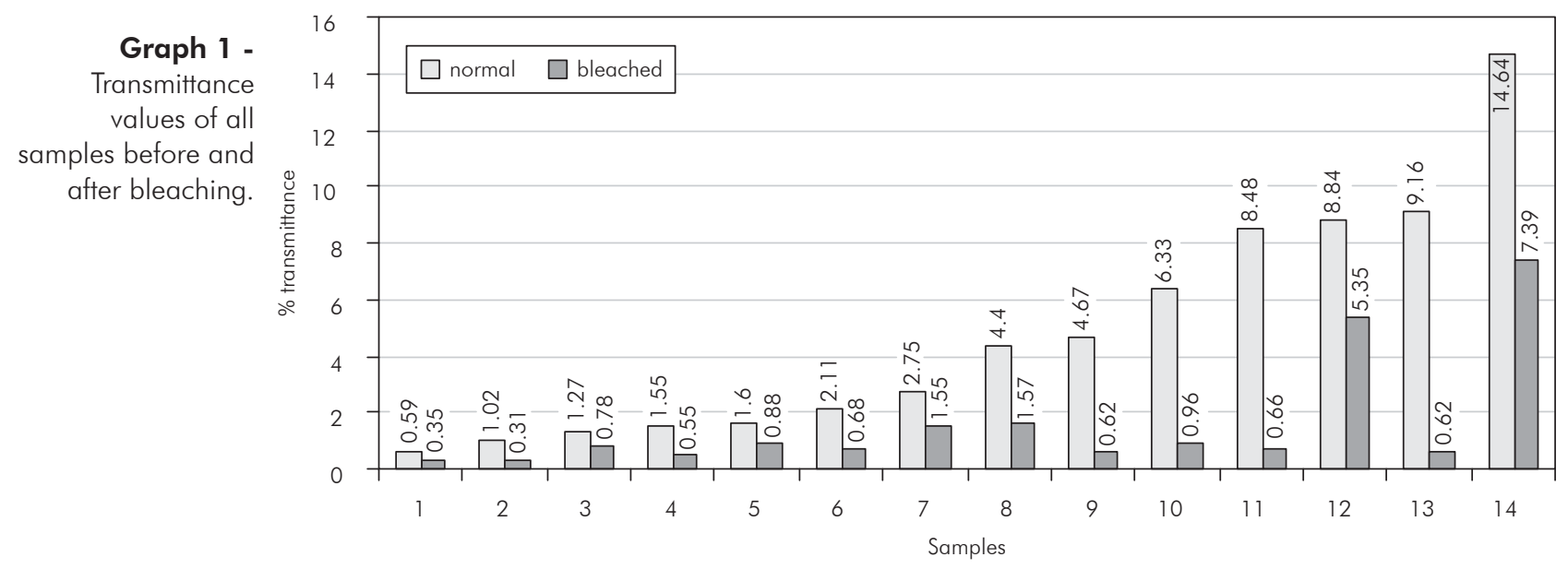

Table 1 - Transmittance values (\%).

\begin{tabular}{l|c|c|c|c}
\hline & $\min$ & $\max$ & Mean & $p$ \\
\hline Normal & 0.59 & 14.64 & 4.815 & 0.003 \\
\hline Bleached & 0.31 & 7.39 & 1.5907 & \\
\hline
\end{tabular}

$p=$ Mann-Whitney test (significance $5 \%$.

\section{Results}

The results are shown on Table 1 . Table 1 shows that there was a statistically significant difference between the groups. There was a decrease in transmittance values for all samples (Graph 1).

An example of the behavior of one specimen for all wavelengths is shown in Graph 2. It was observed that for all emitted wavelengths the transmittance of bleached enamel was lower than that of normal enamel. The same behavior was repeated in all samples.

\section{Discussion}

The sense of sight puts people in contact with the environment through light, which provides the visual sensation of the shape, size and color of objects. In other words, one's interaction with the outside world depends on 3 factors: the object, the viewer and the light. ${ }^{8}$

The color of an object is determined by the light it reflects diffusely. For instance, an object is blue because when a white light falls on it, it diffusively reflects the blue light. This relation between the incident light and the reflected light is known as re-

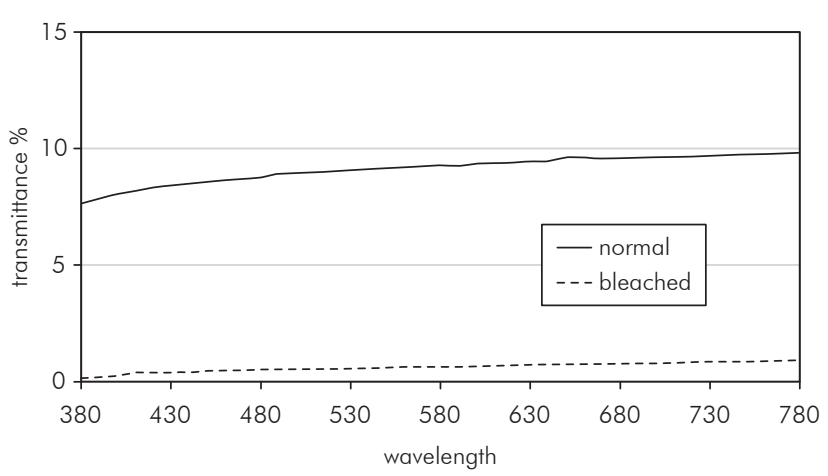

Graph 2 - Transmittance values of sample 10 before and after bleaching.

flectance. Therefore, the color perception of objects relates to their reflectance. However, it must be taken into consideration that there are pigments on the surface of and inside objects, which diffusively reflect part of the incident light. Therefore the color of an object is associated with the reflectance of each of the superficial and internal pigments. ${ }^{9}$

Apart from the light source and the viewer, objects behave differently with regard to light propagation. They can be considered as: transparent, when they allow light propagation and clear visualization of an object through them; translucent, when they allow light propagation, but it is not possible to visualize an object clearly through them; or opaque when the light cannot pass through them. It is also important to consider that once a light falls on an object the specular reflection, diffusive reflection, refraction and absorption phenomena may occur simultaneously. ${ }^{10}$ 
Taking all the previous information into consideration, it can be said that the color of an opaque object depends on the reflectance of each pigment present on its surface. On the other hand, when an object is transparent or translucent, it is necessary to consider the transmittance, which refers to the relation between the incident light and the amount of the light that passes through it. The color of a translucent or a transparent object will result not only from the reflectance of superficial pigments, but also from the reflectance of internal pigments. In other words, the color of a transparent or a translucent object depends on the quality of the pigments (i.e., blue, red, yellow, etc.) and on the quantity of the pigments (or saturation). Therefore, it can be concluded that in transparent or translucent objects, thickness is an important factor: The thicker the object is, the larger the quantity of pigment it contains. ${ }^{8}$

In addition to thickness, the surface smoothness of the object and the background are important factors to consider, because the interaction between them and the type of the object - opaque, translucent or transparent - may interfere in the process of visualizing an object. A further example is given to explain this interaction: Consider an opaque sample, such as a glossy metal slab. If it were roughened, the slab would still be an opaque object, but it would have less brightness or less luminosity. ${ }^{9}$

Background is also an important aspect to consider when observing an object. If a glass slab were placed against a white background and then the same glass slab were placed against a red background, the observer would have the impression that the slab "became" reddish. This occurs because, in both situations, light falls on the glass slab and it is transmitted to the background. However, while the white background reflects all the incident light, the red background returns only the red light to the observer. $^{8}$

Tooth color is determined by the light reflected diffusively by its crown. However the tooth crown is composed of dentine and enamel, which do not have a uniform thickness and are considered opaque and translucent structures, respectively. ${ }^{11}$ This structure will influence the tooth color, because in different regions of the same tooth, the amount of light re- flected, absorbed and/or transmitted by dentine and enamel will be different. ${ }^{12,13}$ Therefore, when a light illuminates a tooth, part of it is reflected by the enamel surface and part of it passes through the enamel and falls on the dentine. In dentine, the light is either absorbed or reflected back to the enamel, passing through it and affecting the observer. ${ }^{14}$ Thus, a change in enamel translucency will modify the optical phenomena described previously, which means that a decrease in enamel translucency, as that observed in this research, leads to a decrease in the incident light on dentine, and, consequently, the influence of dentine color on tooth color will decrease.

In this in vitro research there was a decrease in transmittance values of all samples (Graph 1). Since the light source and the observer were kept constant through the entire experience, and there was no change in sample thickness, the variations in transmittance values are believed to be related to the changes in the translucency of the enamel samples.

There are several researches about dental bleaching using spectrophotometry to evaluate the efficacy of treatment. ${ }^{15-19}$ However the parameters observed in these studies are the color coordinates of the CieLab System ( $L^{*}, a^{*}$ e b*). Therefore it is difficult to compare our results with those of other researches.

Carbamide peroxide, irrespective of its concentration, dissociates into urea and hydrogen peroxide. ${ }^{6}$ The latter degrades into free radicals which, by means of an oxi-reduction chemical process, break down big pigmented molecules and transform them into smaller molecules. ${ }^{20,21}$ The free radicals are unstable and highly reactive, which make them unable to break down the unsaturated bond of organic molecules and promote a change in the absorption spectrum of the radiant light of these molecules. If there were a change in light absorbed, there would be a change in the transmitted and reflected light, which means that there would be a change in the perception of color and in the transmittance values, respectively. ${ }^{22}$

When light reaches a translucent object, it passes through the object and falls on every pigment in the object, and then the light returns to the observer. 
When there is a decrease in the translucency of the object, there will be a decrease in the amount of light that passes through it, and therefore, less light will fall on each pigment. In others words, the object would seem lighter (or less saturated). ${ }^{8}$

The potential change in the enamel surface caused by bleaching agents has been the focus of interest. ${ }^{23,24}$ Many researches observed no significant changes in the enamel surface. ${ }^{6,25-27}$ However, in some researches the following results were observed: oxidation and loss of the aprismatic layer, exposure and demineralization of enamel prisms, oxidation and, possibly, partial removal of the aprismatic layer. ${ }^{28}$

\section{References}

1. Baratieri LN, Monteiro Jr S, Andrada MAC, Vieira LCC. Clareamento Dental. São Paulo: Santos; 1994.

2. Addy M, Moran J, Newcombe R, Warren P. The comparative tea staining potential of phenolic, chlorhexidine and anti-adhesive mouthrinses. J Clin Periodontol. 1995; 22(12):923-8.

3. Hattab FN, Qudeimat MA, Al-Rimawi HS. Dental discoloration: an overview. J Esthet Dent. 1999;11(6):291-310.

4. Haywood VB, Leonard RH, Dickinson GL. Efficacy of six months of nightguard vital bleaching of tetracycline-stained teeth. J Esthet Dent. 1997;9(1):13-9.

5. Leonard Jr RH. Efficacy, longevity, side effects, and patient perceptions of nightguard vital bleaching. Compend Contin Educ Dent. 1998;19(8):766-81.

6. Haywood VB, Houck VM, Heymann HO. Nightguard vital bleaching: effects of various solutions on enamel surface texture and color. Oper Dent. 1991;22:775-82.

7. Steagall Jr W. Contribuição para o estudo da propagação da luz através do esmalte e da dentina humanos [Dissertação de Mestrado]. São Paulo: Faculdade de Odontologia da USP; 2005.

8. Dozic A, Kleverlaan CJ, Aartman IH, Feilzer AJ. Relations in color among maxillary incisors and canines. Dent Mater. 2005;21(3):187-91.

9. Feinman RA, Madray G, Yarborough D. Chemical, optical and physiologic mechanisms of bleaching products: a review. Pract Periodontics Aesthet Dent. 1991;3(2):32-6.

10. Ramalho Jr F, Santos JIC, Ferraro NG, Soares PAT. Os Fundamentos da Física 2 - Termologia, Óptica Geométrica e Ondas. São Paulo: Moderna; 1994.

11. Figún ME, Garino RR. Anatomia Odontológica Funcional e Aplicada. São Paulo: Panamericana; 1997.

12. Bosch JJT, Coops JC. Tooth color and reflectance as related to light scattering and enamel hardness. J Dent Res. 1995;74(1):374-80.
The increase in surface roughness leads to a rise in diffuse reflection and leads to a decrease in the transmitted light, ${ }^{29}$ and consequently, there will be a decrease in the transmittance values. Although this research did not evaluate the surface roughness of specimens before and after the bleaching process, it is possible that the above-mentioned changes occurred, resulting in a decrease in translucency of all specimens.

\section{Conclusion}

It was observed that $10 \%$ carbamide peroxide affected the enamel translucency by decreasing it in all samples.

13. Crocker WP. The cementation of porcelain jacket crowns with adhesive resins. Br Dent J. 1992;172(2):64-7.

14. Phillips RW. Skinner's Science of Dental Materials. Philadelphia: W B Sanders Co.; 1991.

15. Amaechi BT, Higham SM. Development of a quantitative method to monitor the effect of a tooth whitening agent. J Clin Dent. 2002;13(3):100-3.

16. Chu SJ. Use of a reflectance spectrophotometer in evaluating shade change resulting from tooth-whitening products. J Esthet Restor Dent. 2003;15 Suppl 1:S42-8.

17. Gallagher A, Maggio B, Bowman J, Borden L, Mason S, Felix H. Clinical study to compare two in-office (chairside) whitening systems. J Clin Dent. 2002;13(6):219-24.

18. Rustogi KN, Curtis J. Development of a quantitative measurement to assess the whitening effects of two different oxygenating agents on teeth in vivo. Compend Suppl. 1994;(17): S631-4.

19. Viscio D, Gaffar A, Fakhry-Smith S, Xu T. Present and future technologies of tooth whitening. Compend Contin Educ Dent Suppl. 2000 Jun;(28):S36-43; quiz S49.

20. Haywood VB, Heymann HO. Response of normal and tetracycline-stained teeth with pulp-size variation to nightguard vital bleaching. J Prosthet Dent. 1997;6(3):109-14.

21. Oltu U, Gürgan S. Effect of three concentrations of Carbamide peroxide on the structure of enamel. J Oral Rehabil. 2000;27(4):332-40.

22. Seghi RR, Denry I. Effects of external bleaching on indentation and abrasion characteristics of enamel in vitro. J Dent Res. 1992;71(6):1340-4.

23. Spalding M, Taveira LA, de Assis GF. Scanning electron microscopy study of dental surface exposed to $35 \%$ hydrogen peroxide. J Esthet Restor Dent. 2003;15(3):154-65. 
24. Wattanapayungkul P, Yap AU. Effects of in-office bleaching products on surface finish of tooth-colored restorations. Oper Dent. 2003;28(1):15-9.

25. Gultz J, Kaim J, Scherer W, Gupta H. Two in-office bleaching systems: a scanning electron microscope study. Compend Contin Educ Dent. 1999;20(10):965-70.

26. McGuckin RS, Babin JF, Meyer BJ. Alterations in human enamel surface morphology following vital bleaching. J Prosthet Dent. 1992;68(5):754-60.

27. Zalkind M, Arwaz JR, Goldman A, Rotstein I. Surface morphology changes in human enamel, dentin and cementum fol- lowing bleaching: a scanning electron and microscopy study. Endod Dent Traumatol. 1996;12(2):82-8.

28. Bitter NC. A scanning electron microscope study of the effect of bleaching agents on enamel: a preliminary report. J Prosthet Dent. 1992;67(3):852-5.

29. Inokoshi S, Burrow MF, Kataumi M, Yamada T, Takatsu T. Opacity and color changes of tooth-colored restorative materials. Oper Dent. 1996;21(2):73-80. 